\title{
Meals-On-Wheels with Individual Dietary Counseling Can Improve Nutritional Status in Older People
}

\author{
Irma Nykänen ${ }^{1,2,3 *}$ Tiina H Rissanen ${ }^{4}$ and Sirpa Hartikainen ${ }^{1,3}$ \\ ${ }^{1}$ Kuopio Research Centre of Geriatric Care, University of Eastern Finland, Kuopio, Finland \\ ${ }^{2}$ Research Centre for Comparative Effectiveness and Patient Safety (RECEPS), University of Eastern Finland, Kuopio, Finland \\ ${ }^{3}$ School of Pharmacy, Faculty of Health Sciences, University of Eastern Finland, Kuopio, Finland \\ ${ }^{4}$ Institute of Public Health and Clinical Nutrition, Unit of Public Health, University of Eastern Finland, Kuopio, Finland
}

Received: August 26, 2014; Accepted: October 27, 2014; Published: November 10, 2014

*Corresponding author: Irma Nykänen, Kuopio Research Centre of Geriatric Care, Research Centre for Comparative Effectiveness and Patient Safety (RECEPS), Faculty of Health Sciences, University of Eastern Finland, Kuopio Campus, P.0.BOX 1627, FI-70211 Kuopio, Finland, Tel: +35840-355-2991; Fax: 358-17-162-131; E-mail:Irma.Nykanen@uef.fi

\begin{abstract}
Background: A balanced diet and regular meal patterns contribute to health and quality of life among older people. The aim of this study was to evaluate the effects of individual dietary counseling on nutritional status among community-dwelling older people $(\geq 75$ y) receiving Meals-On-Wheels (MOW).

Methods: This study population consisted of 100 communitydwelling participants at risk of malnutrition in the year 2005, intervention group $(n=49)$ and control group $(n=51)$. Data of nutritional status, body weight, body mass index and plasma albumin were collected at the beginning of the study and at a two-year follow-up. The Mini Nutritional Assessment (MNA) test was used for nutritional screening.

Results: Persons in the intervention group improved their nutritional status statistically significantly compared to the control group. The change between groups in MNA score was 3.14 (95\% Confidence Interval [CI]: 1.33 to 4.01 ) and in serum albumin $1.48 \mathrm{~g} / \mathrm{L}$ (95\% CI: 0.02 to $2.93 \mathrm{~g} / \mathrm{L}$ ).

Conclusions: It seems that dietary counseling with MOW improves the nutritional status in older people. MOW should be integrated with nutrition counseling.
\end{abstract}

Keywords: Dietary counseling; Meals-on-wheels; MNA; Nutritional intervention; Older people

\section{Introduction}

The risk of malnutrition is quite common among communitydwelling older people, ranging between 5 and $40 \%$ [1,2]. Several concomitant diseases, the symptoms of depression [3,4], both functional and mental dependency [5,6] and polypharmacy [7] have been associated with an increased risk of malnutrition. Many studies indicate that diet of older people is low in calories and other nutrients [8]. Within the community, efforts have been made to develop nutrition programs targeting older people of high nutritional risk. Meals-On-Wheels (MOW) services are part of this effort. A balanced diet and regular meal patterns contribute to the health and quality of life among the older people
$[9,10]$. Reduced mobility, poor health, and lack of social support all contribute to food insecurity and are common reasons for referral to MOW [11].

In Finland, mass catering plays a key role in the implementation of nutrition policy and catering is also linked to social and welfare policy. About $25 \%$ of Finns aged above 80 years use MOW [12]. Maybe the MOW play an important role in maintaining the nutritional status and health quality $[10,13,14]$. However, this on not supported in the recent studies $[15,16]$ which failed show proof of improvement of the nutritional status of clients without dietary counseling. The aim of this study was to evaluate the effects of individual dietary counseling on nutritional status among community-dwelling people aged 75 years or older receiving MOW.

\section{Methods}

A subgroups analysis of a population-based comparative study, the Geriatric Multidisciplinary Strategy for the Good Care of the Elderly (GeMS) was carried out in the city of Kuopio, Finland, from 2005 to 2007. The present analysis included 100 persons at risk of malnutrition receiving MOW $\geq 2$ times a week, 49 in the intervention and 51 in the control group.

All participants were interviewed and examined yearly by the nurses. Data collection, including nutritional assessment, was supplemented by a caregiver interview if the participant had cognitive impairment. The nutritional screening was performed using the Mini Nutritional Assessment (MNA)-test [17], scores 17.0-23.5 indicate the risk of malnutrition. The MNA test is a validated and standardized screening tool developed to detect nutritional problems in older people. A score of $<17.0$ indicates existing malnutrition, a score of 17.0 to 23.5 a risk of malnutrition, while a score of $\geq 24.0$ indicates a good nutritional status. In this study, the researcher (an authorized nutritionist) trained nurses to use the MNA form, and the nurses completed the forms. The plasma albumin levels were measured according to the standard protocols at the local municipal hospital. Comorbidity was 
computed using the Functional Comorbidity Index (FCI) [18] Cognitive assessment was performed with the Mini-Mental State Examination (MMSE) with scale from 0-30 and higher scores indicating better function [19]. Self-rated health was determined using a 5-step scale (very poor, poor, moderate, good and very good). In the analyses the variable was dichotomized to poor and good self-rated health, with the two first steps representing poor and the three latter good. Use of prescription and nonprescription medications was self-reported by participants during the interviews and verified from prescription forms, drug packages and medical records.

Meal service assessment included questions about how many times MOW were used per week. The participants receiving MOW $\geq 3$ times a week were included in this study.

\section{Nutritional Intervention}

The main aim of the intervention was to help participants improve the wholesomeness of their diet by increasing the frequency of meals and/or adding energy and proteins to the meals without nutritional supplements.

During the first visit in 2005, the authorized nutritionist collected important information such as the client's history of health problems, current dietary intake and specific nutritional problems, food preferences and appetite status. Based on this evaluation, the nutritionist helped the participants draw up their own meal plan with enough energy and proteins. Special leaflets covering topics such as snacking were handed out. Telephone calls once every month by the nutritionist provided opportunities to reinforce the dietary advice and give additional support. Participants' family members were encouraged to attend the dietary counseling sessions. Participants with cognitive impairments had a caregiver present during the sessions; written informed consent was provided by participants and caregivers. During the second visit in 2006, the nutritionist made requisite changes according to the treatment protocol. The participants in the control group did not receive intervention but took part in the annual interviews and measurements.

All participants gave written informed consent to participate in the study. The study protocol was approved by the Research Ethics Committee of the Northern Savo Hospital District, Kuopio, Finland.

\section{Statistical analysis}

The participants receiving MOW were categorized into two groups, the intervention and the control group. Statistical comparisons were made between the groups at the baseline using chi-square test or t-test, with $\leq 0.05$ considered significant. The results were expressed as means or frequencies with Standard Deviations (SD) or percentile. The Mixed Model of linear regression was used to assess the effects of the nutritional status between the years 2005 and 2007. The results were reported as adjusted (age, sex, MMSE) mean differences in MNA and serum albumin. Analyses were performed using SPSS version 19.0. (SPSS, Inc., Chicago, IL).

\section{Results}

Participant characteristics are summarized in Table 1. The mean age of the study population was 83.5 in the intervention group and 84.3 in the control group; in both groups $78 \%$ were women. The proportion cardiovascular disease was $78 \%(n=78)$ and dementia $22 \%(n=22)$ in the whole study sample. One fourth $(25 \%)$ of participants rated their health as poor. At the baseline, there were no statistically significant differences between the intervention and the control group regarding demographic characteristics, nutritional status or cognitive impairment.

After the two-year follow-up, the mean MNA scores improved by 1.21 points in the intervention group and decreased by 1.95 points in the control group (Table 2). Levels of plasma albumin increased in intervention group, but decreased in the control group. The difference in MNA scores [3.14 scores 95\% confidence intervals (CI): 1.33-4.01] and albumin level $(1.48 \mathrm{~g} / \mathrm{L}, 95 \% \mathrm{CI}$ : 0.02-2.93 g/L) between the two groups was significant after adjustment for age, sex and MMSE scores.

\section{Discussion}

According to our study, nutritional counseling for older persons receiving the MOW improved their nutritional status. However the MOW without dietary counseling impaired their nutritional status measured by the MNA scores and plasma albumin levels.

Recipients of the MOW are vulnerable, with several health problems and disabilities [20,21]. Previous studies have shown

Table 1: Characteristics of participants with risk of malnutrition and meals on wheels by study groups.

\begin{tabular}{|c|c|c|c|}
\hline & $\begin{array}{l}\text { Intervention } \\
\text { group }(N=49) \\
\text { mean }(S D)\end{array}$ & $\begin{array}{l}\text { Control group } \\
(\mathrm{N}=51) \\
\text { mean (SD) }\end{array}$ & $\begin{array}{l}P \\
\text { value }\end{array}$ \\
\hline Age & $83.5(4.8)$ & $84.3(4.2)$ & 0.481 \\
\hline Women & $38(77.6)$ & $40(78.4)$ & 0.849 \\
\hline BMI kg/m² & $26.7(5.4)$ & $26.1(4.7)$ & 0.981 \\
\hline MNA & $21.7(5.5)$ & $22.7(3.0)$ & 0.367 \\
\hline Albumin g/L & $35.3(3.2)$ & $35.9(3.8)$ & 0.639 \\
\hline FCI, mean (SD) & $3.4(1.9)$ & $3.5(2.0)$ & 0.641 \\
\hline $\begin{array}{l}\text { Cardiovascular disease, } \\
\mathrm{n}(\%)\end{array}$ & 38 (77.6) & $40(78.4)$ & 0.767 \\
\hline Dementia, n(\%) & $11(22.4)$ & $11(21.6)$ & 0.812 \\
\hline MMSE $\leq 24, \mathrm{n}(\%)$ & $27(55.1)$ & $26(50.1)$ & 0.106 \\
\hline $\begin{array}{l}\text { Poor self-rated health, } \\
\mathrm{n}(\%)\end{array}$ & $12(24.5)$ & $13(25.5)$ & 0.656 \\
\hline $\begin{array}{l}\text { Drugs in regular use, } \\
\text { median (IQR) }\end{array}$ & $5(3-7)$ & $5(3-8)$ & 0.976 \\
\hline IADL, median (IQR) & $6(3-7)$ & $6(4-7)$ & 0.988 \\
\hline $\begin{array}{l}\text { Walks } 400 \mathrm{~m} \\
\text { independently, n (\%) }\end{array}$ & 35 (71.4) & $35(68.6)$ & 0.265 \\
\hline
\end{tabular}

SD = Standard deviations; BMI = Body mass index; MNA = Mini Nutritional Assessment; FCI = Functional Comorbidity Index; MMSE = Mini Mental State Examination; IQR = interquartile range 
Table 2: Changes in nutritional status from baseline to 2-years and differences between intervention and control groups among meals-on-wheels users.

\begin{tabular}{|l|l|l|l|}
\hline & $\begin{array}{l}\text { Mean change } 2005 \text { to } 2007(\mathbf{9 5 \%} \mathbf{C I}) \\
\text { Intervention group }(\mathbf{n}=\mathbf{4 9})\end{array}$ & $\begin{array}{l}\text { Mean change 2005 to 2007 } \mathbf{9 5 \%} \text { CI) } \\
\text { Control group (n= 51) }\end{array}$ & $\begin{array}{l}\text { Mean difference } \\
\text { between groups* } \\
\text { (95\% CI) }\end{array}$ \\
\hline MNA, score & $1.21(-0.42$ to 2.68$)$ & $-1.95(-0.92$ to 2.90$)$ & $3.14(1.33$ to 4.01$)$ \\
\hline Albumin g/L & $1.87(0.61$ to 3.12$)$ & $-0.38(-1.92$ to 1.25$)$ & $1.48(0.02$ to 2.93$)$ \\
\hline
\end{tabular}

*Adjusted for age, sex and MMSE

MNA = Mini Nutritional Assessment; MMSE = Mini-Mental State Examination

that majority of recipients of the MOW (74\% to 98\%) were at nutritional risk [22,23]. Furthermore, many older people have physical problems that make it difficult for them to consume certain foods [10]. According to our findings a previous study [24] found that nutritional counseling has a significant impact on the nutritional status and health of persons receiving the MOW service. Appropriate nutritional intervention for the recipients of the MOW seems to improve nutritional status.

The MOW service is based on the assumption that all food in the meal is actually consumed, which leads to an overoptimistic impression of the nutritional value of the meals. This is supported in the results of Roy and Payette's study were nineteen subjects (95\%) usually or never consumed their entire meal, and eight $(40 \%)$ subjects reported that they threw away parts of their meal [21]. The reasons for throwing out part of the meal maybe unappetizing food, food with unsuitable textures or portions are too big [25-27]. However, two-thirds (67\%) of recipients were satisfied with meal quality, time of delivery, variety, choice, and temperatures of foods most of the time although they cannot choose their own foods [25,27].

In our study, the positive effect of dietary counseling on nutritional status might be explained by the individually tailored interventions for persons in the intervention group. The nutritionist increased the frequency of meals and added energy and proteins to the meals case-specifically. The beneficial effect of the intervention among persons at risk of malnutrition is important from a public health viewpoint, as the risk of malnutrition, even malnutrition, is common among communitydwelling older people and when left under-treated, causes many difficulties. More attention should be given to this group to improve their health status with energy- and protein-rich food.

The strengths of the present study were the population-based design, the fact that participants underwent comprehensive interviews and assessments, as well as the fact that the study design and data collection was conducted by a multiprofessional research team. The nutrition intervention included individually tailored personal guidance on nutrition, so it may be assumed that dietary counseling was more likely to be adopted by the participants. Furthermore, the nutrition intervention was performed by the same authorized nutritionist. A limitation was the low participation rate in the nutritional intervention. The design of the study is weaker than a traditional randomized controlled trial, owing to randomization having been performed before the baseline measurements.

\section{Conclusion}

Dietary counseling with the MOW improves the nutritional status in older people. MOW should be integrated with nutrition counseling.

\section{Acknowledgments}

The authors wish to acknowledge the GeMS study personnel, physicians Marja-Liisa Laitinen, Sirpa Pikkarainen and Jarmo Ålander, nutritionist Anne Tuovinen, nurses Anu Hänninen, Paula Iire and Marja-Leena Kekäläinen for their dedicated work collecting data for this project.

\section{Funding support}

The Geriatric Multidisciplinary Strategy for the Good Care of the Elderly (GeMS) Study was supported by grants from the Social Insurance Institution of Finland and City of Kuopio. Authors declare that there is no conflict of interest.

\section{References}

1. Kaiser MJ, Bauer JM, Rämsch C, Uter W, Guigoz Y, Cederholm T, et al. Frequency of malnutrition in older adults: a multinational perspective using the mini nutritional assessment. J Am Geriatr Soc. 2010; 58: 1734-1738. doi: 10.1111/j.1532-5415.2010.03016.x.

2. Nykänen I, Rissanen TH, Sulkava R, Hartikainen S. Effects of individual dietary counseling as part of a comprehensive geriatric assessment (CGA) on nutritional status: a population-based intervention study. J Nutr Health Aging. 2014; 18: 54-58. doi: 10.1007/s12603-0130342-y.

3. Iizaka S, Tadaka E, Sanada H. Comprehensive assessment of nutritional status and associated factors in the healthy, community-dwelling elderly. Geriatr Gerontol Int. 2008; 8: 24-31. doi: 10.1111/j.14470594.2008.00443.x.

4. Ülger Z, Halil M, Kalan I, Yavuz BB, Cankurtaran M, Güngör E, et al. Comprehensive assessment of malnutrition risk and related factors in a large group of community-dwelling older adults. Clin Nutr. 2010; 29: 507-511. doi: 10.1016/j.clnu.2010.01.006.

5. Ferdous T, Cederholm T, Razzaque A, Wahlin A, Nahar Kabir Z. Nutritional status and self-reported and performance-based evaluation of physical function of elderly persons in rural Bangladesh. Scand J Public Health. 2009; 37: 518-524. doi: 10.1177/1403494809102778.

6. Nykänen I, Lönnroos E, Kautiainen H, Sulkava R, Hartikainen S. Nutritional screening in a population-based cohort of communitydwelling older people. Eur J Public Health. 2013; 23: 405-409. doi: 10.1093/eurpub/cks026.

7. Jyrkkä J, Enlund H, Lavikainen P, Sulkava R, Hartikainen S. Association 
of polypharmacy with nutritional status, functional ability and cognitive capacity over a three-year period in an elderly population. Pharmacoepidemiol Drug Saf. 2011; 20: 514-522. doi: 10.1002/ pds.2116.

8. Locher JL, Robinson CO, Roth DL, Ritchie CS, Burgio KL. The effect of the presence of others on caloric intake in homebound older adults. Gerontol A Biol Sci Med Sci. 2005; 60: 1475-1478.

9. Keller HH, Gibbs AJ, Boudreau LD, Goy RE, Pattillo MS, Brown HM. Prevention of weight loss in dementia with comprehensive nutritional treatment. J Am Geriatr Soc. 2003; 51: 945-952.

10. Keller HH. Nutrition and health-related quality of life in frail older adults. J Nutr Health Aging. 2004; 8: 245-252.

11. Lee JS, Frongillo EA Jr. Factors associated with food insecurity among U.S. elderly persons: importance of functional impairments. J Gerontol B Psychol Sci Soc Sci. 2001; 56: S94-99.

12. Alden-Nieminen H, Raulio S, Männistö S, Laitalainen E, Suominen M, Prättälä R. Meal patterns among the Finnish elderly. Monitoring project of mass catering. 2009.

13. Millen BE, Ohls JC, Ponza M, McCool AC. The elderly nutrition program: an effective national framework for preventive nutrition interventions. J Am Diet Assoc. 2002; 102: 234-240.

14. Keller HH. Meal programs improve nutritional risk: a longitudinal analysis of community-living seniors. J Am Diet Assoc. 2006; 106 1042-1048.

15. Saletti A, Johansson L, Yifter-Lindgren E, Wissing U, Osterberg K, Cederholm T. Nutritional status and a 3-year follow-up in elderly receiving support at home. Gerontology. 2005; 51: 192-198.

16. Beck AM, Hansen KS. Meals served in Danish nursing homes and to Meals-on-Wheels clients may not offer nutritionally adequate choices J Nutr Elder. 2010; 29: 100-109. doi: 10.1080/01639360903574742.

17. Guigoz Y, Vellas B, Garry PJ. Assessing the nutritional status of the elderly: The Mini Nutritional Assessment as part of the geriatric evaluation. Nutr Rev. 1996; 54: S59-65.

18. Groll DL, To T, Bombardier C, Wright JG. The development of a comorbidity index with physical function as the outcome. J Clin Epidemiol. 2005; 58: 595-602.

19. Crum RM, Anthony JC, Bassett SS, Folstein MF. Population-based norms for the Mini-Mental State Examination by age and educational level. JAMA. 1993; 269: 2386-2391.

20. Krondl M, Lau D, Coleman P, Stocker G. Tailoring of nutritional support for older adults in the community. J Nutr Elder. 2003; 23: 17-32.

21. Roy MA, Payette H. Meals-on-wheels improves energy and nutrient intake in a frail free-living elderly population. J Nutr Health Aging. 2006; 10: 554-560.

22. Sharkey JR, Haines PS. Nutrition risk screening of home-delivered meal participants: relation of individual risk factors to functional status. Journal of Nutrition For the Elderly. 2002. 22:15-34.

23. Coulston AM, Craig L, Voss AC. Meals-on-wheels applicants are a population at risk for poor nutritional status. J Am Diet Assoc. 1996; 96: 570-573.

24. Wunderlich S, Bai Y, Piemonte J. Nutrition risk factors among home delivered and congregate meal participants: need for enhancement of nutrition education and counseling among home delivered meal participants. J Nutr Health Aging. 2011; 15: 768-773.

25. Frongillo EA, Isaacman TD, Horan CM, Wethington E, Pillemer K. Adequacy of and satisfaction with delivery and use of home-delivered meals. J Nutr Elder. 2010; 29: 211-226. doi: $10.1080 / 01639361003772525$.

26. Lirette T, Podovennikoff J, Wismer W, Tondu L, Klatt L. Food preferences and meal satisfaction of meals on wheels recipients. Can J Diet Pract Res. 2007; 68: 214-217.

27. Joung HW, Kim HS, Yuan JJ, Huffman L. Service quality, satisfaction, and behavioral intention in home delivered meals program. Nutr Res Pract. 2011; 5: 163-168. doi: 10.4162/nrp.2011.5.2.163. 